\title{
Modelling of Incident Wave Sound Absorption Coefficient of Paper Sludge Panels
}

\author{
Tomas Astrauskas (iD*, Raimondas Grubliauskas \\ Department of Environmental Protection and Water Engineering, \\ Vilnius Gediminas Technical University, Vilnius, Lithuania
}

Received 03 March 2020; accepted 31 March 2020

\begin{abstract}
Paper sludge is the water treatment waste, which produced during paper production. Paper sludge (PS) waste utilization is the common problem in the EU and internationally. According to authors Frías et al. paper sludge is the main waste in the paper processing factories, the percentage reach $35 \%$ of product volume. According to the waste management directive No. 2008/98/EC, paper sludge waste should not be utilised in landfills. Such legislation generates the motivation of this study. This study deals with paper sludge as sound absorbing material.

In this paper panels made of paper sludge is studied. Sound absorption coefficient of the panels predicted with Horoshenkov and Swift acoustic model for granular media. The aim of this paper is to predict sound absorption coefficient using non-acoustic parameters of the material.
\end{abstract}

Keywords: modelling, sound absorption coefficient, paper sludge, granular materials, Horoshenkov and Swift model, sample thickness, grain size.

\section{Introduction}

Paper sludge (PS) is the water treatment waste, produced during paper production. PS waste is a common problem in the European Union (EU) and internationally (Bajpai, 2015). According to (Frías et al., 2015), paper sludge is the main waste in the paper processing factories, with a high $35 \%$ of the product volume. According to the waste EU management directive No. 2008/98/EC, utilizing paper sludge waste in landfills is forbidden.

One of the solutions to recycle paper sludge is to use it as construction materials. The studies made by several authors show that such material chemical composition and its properties have huge potential to introduce its use in the building material sector (Malaiskiene et al., 2018; de Azevedo et al., 2019). Recent studies regarding paper sludge propose to build composite materials for heat insulation purposes (lack of reference here). In (Soucy et al., 2014) it is shown that increasing the paper sludge content in wood-plastic composites enhances the water absorption property of composite (what composite) and reduces the composite strength. A similar study (describe a bit the study) was made by Donmez Cavdar et al. on wood cement and paper sludge composites (Donmez Cavdar et al., 2017). When the paper sludge quantity increased thickness swelling tends to increase as well. In (Goel \& Kalamdhad, 2017), authors find that the addition of paper sludge increases the total porosity of the brick but, decreases the strength. Hydration, mechanical, thermal insulation and sound-absorbing properties of paper sludge ash and cement composites are analysed in (Doudart de la Grée et al., 2018). A composition of 51\% cement, $29 \%$ limestone powder and $20 \%$ paper sludge ash the porosity of the composite reaches $75 \%$ and its density is over $400 \mathrm{~kg} / \mathrm{m}^{3}$. Such composition according to the authors could reach a sound absorption coefficient up to 0.8 in higher frequencies.

Paper sludge can be characterized as a granular material. Many studies have been done regarding the different types of granular materials (Shumway, 1960; Horoshenkov \& Swift, 2002; Pfretzschner, 2002; Urick, 2005; Asdrubali \& Horoshenkov, 2009; Sukontasukkul, 2009; Horoshenkov, 2017). The granular material non-acoustic parameters mainly influenced by geometrical parameters of grain. The geometrical parameters include grain size and shape of each grain. These grain parameters are related to the porosity of the media (Asdrubali et al., 2007). Asdrubali, D'Alessandro, and Schiavoni studied the grain size influence on rubber crumb on the sound absorption coefficient. The findings showed that increasing the grain size shifts the sound absorption maxima to the higher frequencies (Asdrubali et al., 2008). In another study of Buratti, Merli, and Moretti the same dependency was found in the silica aerogel granular material (Buratti et al., 2017).

${ }^{*}$ Corresponding author. E-mail: tomas.astrauskas@vgtu.lt 
The main non-acoustic property of materials that determine the sound absorption potential of materials is the airflow resistivity of the material. Granular materials as the mineral wool or foams are considered to be porous and the acoustic impedance and ultimately sound absorption could be predicted by the well-known formulations of DelanyBazley and Miki (Delany \& Bazley, 1970; Miki, 1990; Pfretzschner, 2002). However, the authors Horoshenkov and Swift proposed a formulation to estimate the sound absorption coefficient for granular materials (Horoshenkov \& Swift, 2002; Horoshenkov, 2017). In these formulations to predict sound absorption of the granular media, several non-acoustic parameters are needed: airflow resistivity $\sigma$, porosity $\varphi$ and grain size of granular media.

Different granular materials absorb sound differently due to the different shapes and the size of the grains. Because it is not possible for the grains to coalesce perfectly on top of each other over the sample area, the air resistance and sound absorption will be different in the sample area (Brzinski et al., 2013; Horoshenkov, 2017). Acoustically, rubber and sand granules are much-studied (Shumway, 1960; Pfretzschner \& Rodriguez, 1999; Urick, 2005; Sukontasukkul, 2009; Gayathri et al., 2013). Like any porous material, the sound absorption of granular materials depends on the airflow resistivity and thickness of the material. The airflow resistivity in granular materials depends on the particle shape of the granules. If the particles are of regular shape, they will have fewer gaps for air to pass, resulting in higher air resistance, and thus sound absorption of the granular material (Pfretzschner \& Rodriguez, 1999).

The waste management legislation generates the motivation of this study on paper sludge as sound absorptive material. This study deals with paper sludge as a sound-absorbing material. Very few studies mention the acoustic properties or improvements regarding sound insulation or absorption. The aim of this study was to predict the sound absorption of paper sludge panels.

\section{Methods and materials}

The study consists of two parts: the experimental part and the theoretical part. Airflow resistance and porosity of paper sludge were determined experimentally. The sound absorption of the paper sludge was predicted in accordance with the theoretical model for granular media by Horoshenkov and Swift.

The static airflow method used to determine the material airflow resistivity. This method based on the air pressure difference between the two open-material surfaces. Standpipe length should be long enough to ensure as close as possible to laminar directional airflow. The specimen holder shall be $50 \%$ of the cross-sectional area and have evenly spaced open holes $10 \mathrm{~mm}$ in diameter. To create an air pressure compressor was used, and a pressure difference was measured with the differential pressure gauge, with a precision of $0.1 \mathrm{~Pa}$. The air velocity is measured with the airflow velocity tester. The air velocity in the unit was $0.01 \mathrm{~m} / \mathrm{s}^{2}$. The air velocity did not influence the pressure difference before and after the material. The method is based on the ISO 9053 standard. The scheme of measurement system presented in Figure 1.

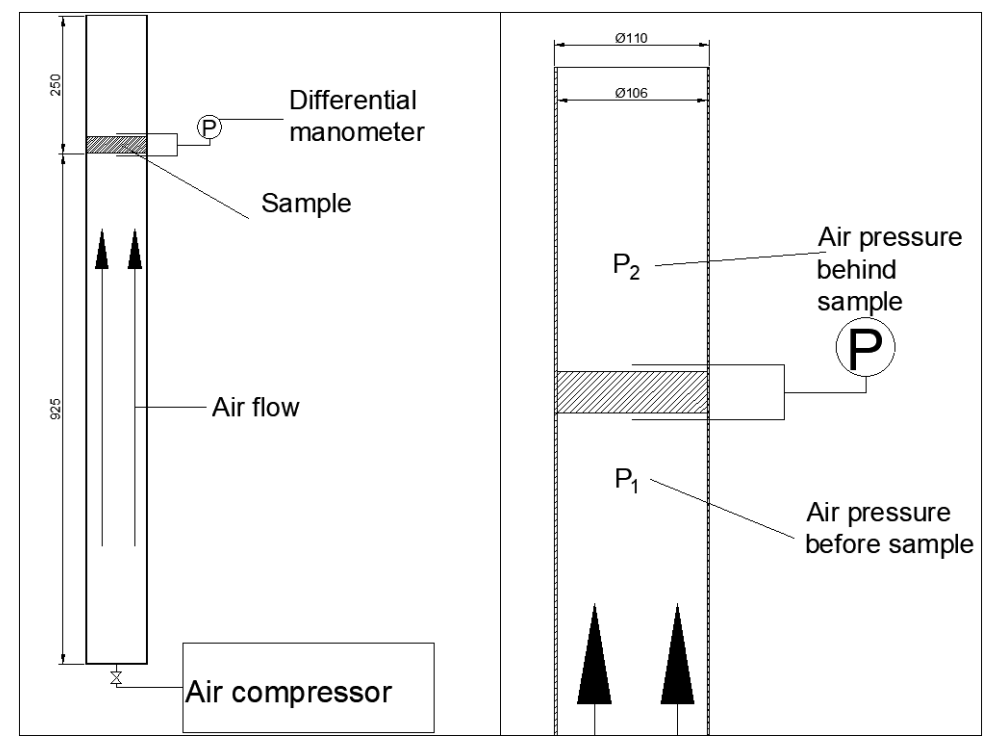

Figure 1 . Airflow resistivity measurement system

In order to determine airflow resistance the difference in air pressure and air velocity $v$ has to be measured.

$$
\Delta P=P_{1}-P_{2},
$$

where: $\Delta P$ - differential pressure, $\mathrm{Pa} ; P_{1}-$ air pressure in front of the sample, $\mathrm{Pa} ; P_{2}-$ air pressure behind the sample, Pa. 
The airflow resistance $\mathrm{R}$ is calculated using formula (2):

$$
R=\frac{\Delta P}{q v}
$$

where $q$-airflow rate through the sample, $\mathrm{m}^{3} / \mathrm{s}$.

After that the specific airflow resistance is being calculated, this parameter is determined as a multiplication of airflow resistance and the sample area.

$$
R_{s}=R A,
$$

where $A$ - Surface area of the sample.

Finally, static airflow resistivity is determined as a ratio between the specific airflow resistance and thickness of the sample:

$$
\sigma=\frac{R_{S}}{d}
$$

where $d$ - thickness of the sample, m.

The sound absorption is calculated using Horoshenkov and Swift model. The main material parameters, describing the granular media sound absorption are the airflow resistance, tortuosity and porosity.

$$
k=\omega \sqrt{\alpha_{\infty} \rho_{0} / \gamma P_{0}},
$$

where: $k$ - complex wave number, $\omega-$ angular frequency $\mathrm{rad} / \mathrm{s}, \alpha_{\infty}-$ tortuosity, $\rho_{0}-$ air density $\mathrm{kg} / \mathrm{m}^{3}$ $\rho_{0}=1.213 \mathrm{~kg} / \mathrm{m}^{3}, P_{0}$ - atmospheric pressure $\mathrm{Pa}, P_{0}=1.213 \cdot 10^{5} \mathrm{~Pa}, \gamma$ - specific heat ratio $\gamma=1.4$.

The tortuosity of the material is porosity dependent parameter and for granular media could be calculated according to formula (6):

$$
\alpha_{\infty}=1+\frac{1-\varphi}{2 \varphi}
$$

where: $\alpha_{\infty}$ - tortuosity, $\varphi$ - porosity of the material, $\%$.

According to the Champoux-Allard model, effective density calculated according to formula No. 7 (Allard et al., 1989; Panneton \& Olny, 2006):

$$
\rho_{e}=k_{s} \rho_{0}\left[1+\frac{\sigma \varepsilon}{j \omega k_{s} \rho_{0}} \sqrt{1+\frac{4 k k_{s}^{2} \eta \rho_{0} \omega}{\sigma^{2} \Lambda^{2} \varepsilon^{2}}}\right],
$$

where: $\rho_{e}$ - effective density, $k_{s}$ - tortuosity, $\eta$ - viscosity $\Lambda$ - characteristic thermal length.

Bulk modulus is calculated according to the same model (Sánchez-Orgaz et al., 2019):

$$
K_{e}=\frac{\gamma P_{0}}{\gamma-(\gamma-1) /\left(1+\frac{8 \eta}{j \Lambda^{2} N_{p} \omega \rho} \sqrt{1+\frac{j \rho \omega N_{p} \Lambda^{2}}{16 \eta}}\right)},
$$

where: $\gamma$ - Specific heat ratio, $P_{0}$ - atmospheric pressure, $\mathrm{Pa}, N_{p}$ - correction coeficient (0.77).

From those two models described the characteristic acoustic impedance can be calculated:

$$
Z_{c}=\sqrt{K_{e} \rho_{e}} .
$$

The specific surface acoustic impedance is calculated according formula (10):

$$
Z_{s}=-j \frac{Z_{C}}{\varphi} \cot (k d),
$$

where: $Z_{s}$ - specific acoustic impedance, Pas $/ \mathrm{m}^{3}, k$-wave number, $d$ - thickness of the sample, $\mathrm{m}$.

The sound reflection coefficient of the can be can be calculated as (Doutres et al., 2010): 


$$
R=\frac{\frac{z_{s}}{\rho_{0} c_{0}} \cos (f)-1}{\frac{z_{s}}{\rho_{0} c_{0}} \cos (f)+1},
$$

where $R$ - sound reflection coefficient.

The sound absorption coefficient calculated according to formula (12) (Panneton, 2017):

$$
\alpha=1-|R|^{2} .
$$

where $\alpha$ - sound absorption coefficient.

The paper sludge dried at $60{ }^{\circ} \mathrm{C}$ prior to sample preparation. Afterwards, the dried sludge crushed with a gill crusher then sifted and sorted according to the grain size. After that, the samples were formed using water as a binder. Airflow resistivity was measured using the described method. The samples were produced in special 3D printed perforated boxes to ensure diffuse water evaporation. To ensure diffuse evaporation the samples flipped on the opposite side every 24 hours. The time of sample making is 7 days. The box for sample presented in Figure 2.
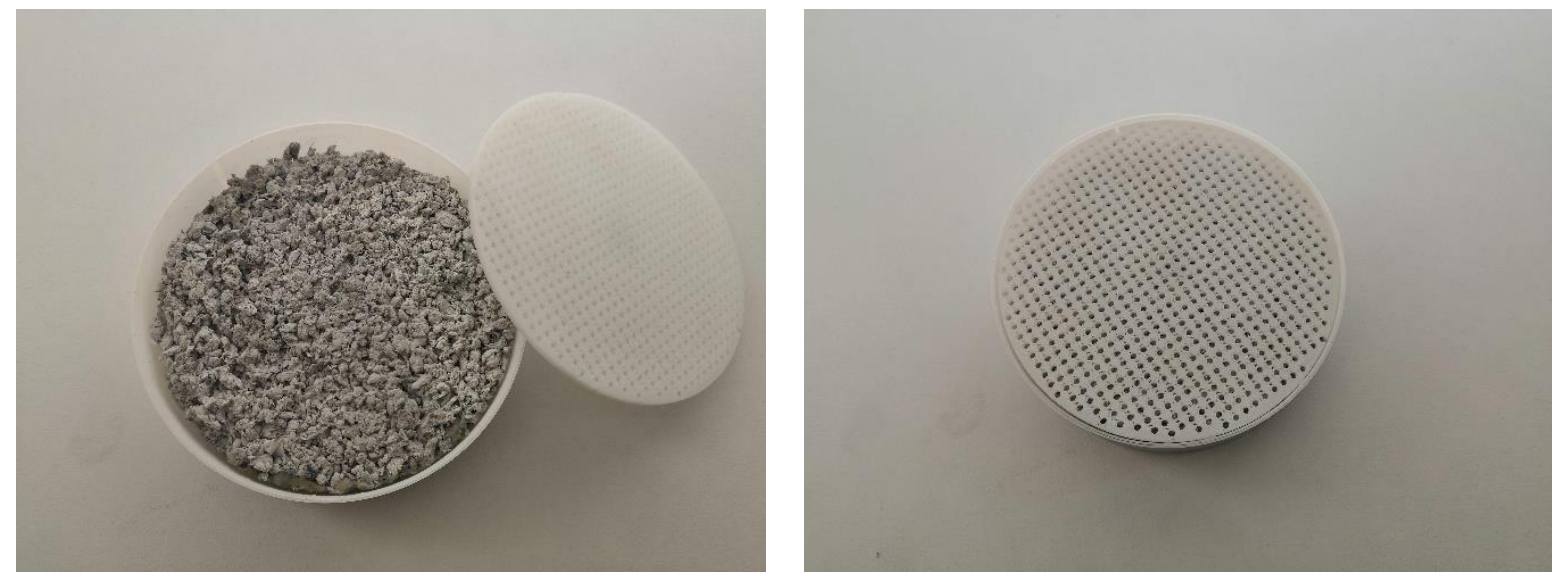

Figure 2. The box for sample making and the sample

For the modelling purposes three different grain size samples were chosen for this study: $1-2.5 \mathrm{~mm} ; 2.5-5 \mathrm{~mm}$; 5-10 mm. Each grain size contributes to different porosity values.

The porosity of the samples was measured using the water saturation method. The water was poured on the sample until it forms a film above the sample, the volume of water used was measured. Since the samples made in the box, the volume of the samples is known and porosity of the sample could be calculated according to the formula (13):

$$
\varphi=\frac{V_{w}}{V_{s}},
$$

where: $V_{w}$ - The volume of the used water, $V_{s}$ - the volume of the sample.

\section{Results}

The experimental results are shown in Table 1. As expected, the airflow resistivity increases as grain size decreases and the porosity values are inversely proportional. The values of airflow resistivity differ from 14.5 to 28.5 and porosity values differ from 0.82 to 0.91 dependent on grain size.

Table 1. Main parameters of the samples

\begin{tabular}{|c|c|c|c|}
\hline Sample & Grain size & Airflow resistivity, $\sigma, \mathrm{KPa} / \mathrm{m}^{2}$ & Open porosity, $\varphi$ \\
\hline No. 1 & $5-10 \mathrm{~mm}$ & $14.5 \pm 0.76$ & $0.91 \pm 0.01$ \\
\hline No. 2 & $2.5-5 \mathrm{~mm}$ & $21.0 \pm 0.87$ & $0.85 \pm 0.02$ \\
\hline No. 3 & $1-2.5 \mathrm{~mm}$ & $28.5 \pm 0.5$ & $0.82 \pm 0.02$ \\
\hline
\end{tabular}


The Horoshenkov and Swift model used to predict granular material incident wave sound absorption coefficient. The directly measured values of airflow resistivity and porosity used in a model to predict sound absorption coefficient values of the paper sludge panels.

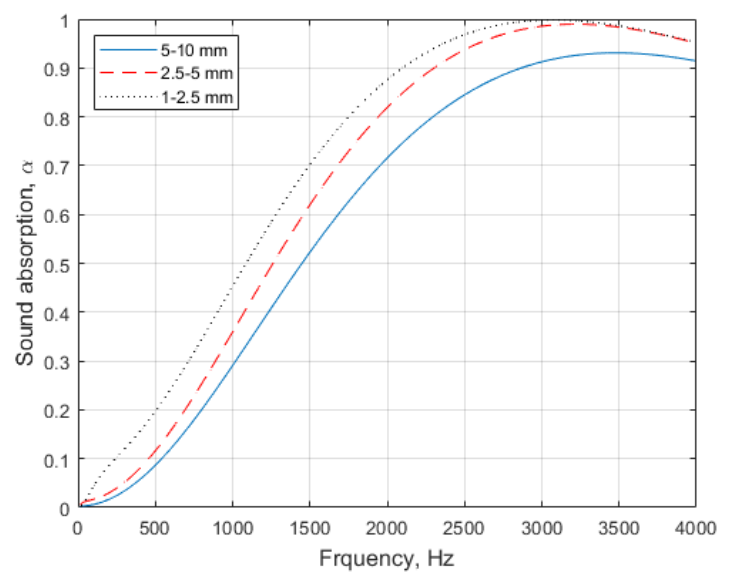

Figure 3. Influence of grain size on sound absorption, sample thickness $3 \mathrm{~cm}$

In Figure 3 influence of grain size on the sound absorption coefficient is presented. The modelling results show that sound absorption coefficient values increase as grain size decrease. The smaller grain size increases the viscous thermal and characteristic viscous thermal length, which leads to higher sound absorption coefficient values. According to prediction results, $1-2.5 \mathrm{~mm}$ grain size sample $\alpha$ coefficient reaches 0.98 .

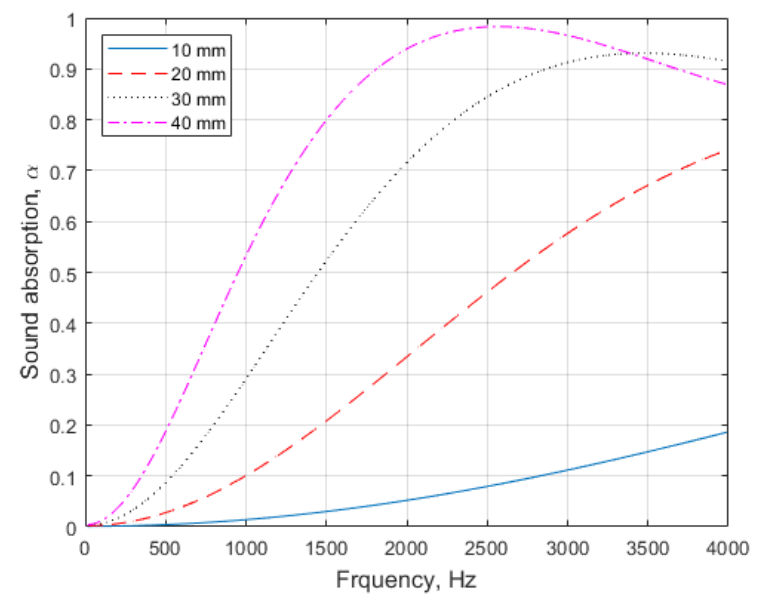

Figure 4. Influence of sample thickness on sound absorption coefficient, grain size 5-10 mm

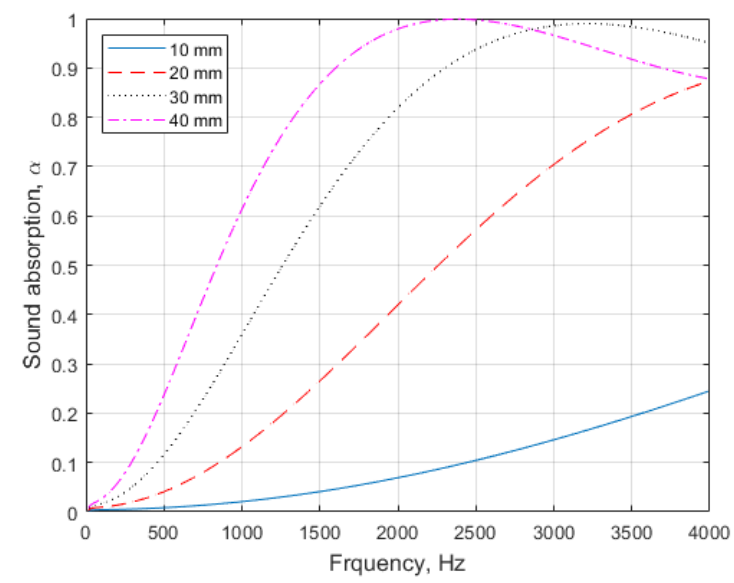

Figure 5. Influence of sample thickness on sound absorption coefficient, grain size 2.5-10 mm 
The influence of sample thickness on sound absorption of different materials is well known and studied by numerous authors. It is known that the peak of sound absorption coefficient shifts to lower frequencies when sample thickness is increased. Although the paper sludge is new material to use for sound absorption purposes and it is interesting to know, what sample thickness should be most rational for different situations of application. The influence of sample thickness (grain size 5-10 mm) presented in Figure 4. The sound absorption coefficient of $10 \mathrm{~mm}(\alpha$ reach 0.19 ) and $20 \mathrm{~mm}$ ( $\alpha$ reach 0.73$)$ sample is relatively low, compared with $30 \mathrm{~mm}$ ( $\alpha$ reach 0.93$)$ and $40 \mathrm{~mm}(\alpha$ reach 0.97) sample thickness.

The influence of sample thickness (grain size 2.5-10 mm) presented in Figure 5. The sound absorption coefficient of $10 \mathrm{~mm}$ ( $\alpha$ reach 0.24 ) and sample is relatively low, compared with $20 \mathrm{~mm}$ ( $\alpha$ reach 0.87$), 30 \mathrm{~mm}(\alpha$ reach 0.97$)$ and $40 \mathrm{~mm}$ ( $\alpha$ reach 0.99) sample thickness. As in Figure 1 smaller grain size samples show the higher sound absorption coefficient values compared with 5-10 mm grain size sample.

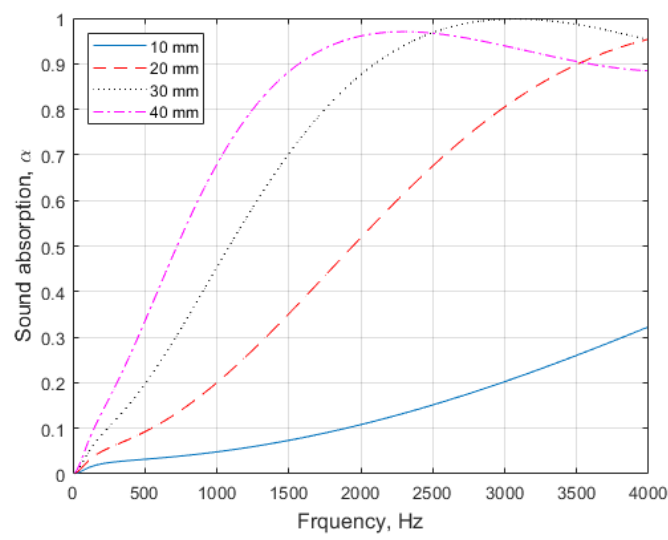

Figure 6. Influence of sample thickness on sound absorption coefficient, grain size 1-2.5 mm

The influence of sample thickness (grain size 1-2.5 mm) presented in Figure 6. The sound absorption coefficient of $10 \mathrm{~mm}$ ( $\alpha$ reach 0.33 ) sample is relatively low, compared with $20 \mathrm{~mm}$ ( $\alpha$ reach 0.95$), 30 \mathrm{~mm}(\alpha$ reach 0.99$)$ and $40 \mathrm{~mm}(\alpha$ reach 0.97$)$ sample thickness.

\section{Conclusions}

This paper studies the grain size and thickness influence on sound absorption. In all calculated sound absorption values, the peak sound absorption gained when sample thickness reaches $1 / 4$ of wavelength. The modelling results showed that smaller grain size samples should have higher sound absorption values compared with bigger grain size samples. When the thickness of the sample increases peak sound absorption values shifts to lower frequencies. The predicted sound absorption $\alpha$ values reach up to 0.99 when $1-2.5 \mathrm{~mm}$ grain size of paper sludge used. The bigger grain size of paper sludge reduces the overall sound absorption coefficient values. When increasing the thickness of the sample it is predicted that $10 \mathrm{~mm}$ and $20 \mathrm{~mm}$ thickness is not rational for sound absorption applications, due to relatively low sound absorption coefficient values compared with 30-40 $\mathrm{mm}$ thickness samples. When paper sludge is used for sound absorption applications it is recommended to use not less than $3 \mathrm{~cm}$ thickness.

\section{Funding}

The authors received no specific funding for this work.

\section{References}

Allard, J. F., Depollier, C., \& Guignouard, P. (1989). Free field surface impedance measurements of sound-absorbing materials with surface coatings. Applied Acoustics, 26(3), 199-207. https://doi.org/10.1016/0003-682X(89)90053-4

Asdrubali, F., Baldinelli, G., \& D’Alessandro, F. (2007). Evaluation of the acoustic properties of materials made from recycled tyre granules. Paper presented at the Proceedings of the $36^{\text {th }}$ International Congress and Exhibition on Noise Control Engineering, Istanbul, Turkish.

Asdrubali, F., D'Alessandro, F., \& Schiavoni, S. (2008). Sound absorbing properties of materials made of rubber crumbs. The Journal of the Acoustical Society of America, 123(5). https://doi.org/10.1121/1.2932706

Asdrubali, F., \& Horoshenkov, K. V. (2009). The acoustic properties of expanded clay granulates. Building Acoustics, 9(2), 85-98. https://doi.org/10.1260/135101002760164553 
Bajpai, P. (2015) Management of pulp and paper mill waste. Springer. https://doi.org/10.1007/978-3-319-11788-1

Brzinski, T. A., Mayor, P., \& Durian, D. J. (2013). Depth-dependent resistance of granular media to vertical penetration. Physical Review Letters, 111(16). https://doi.org/10.1103/PhysRevLett.111.168002

Buratti, C., Merli, F., \& Moretti, E. (2017). Aerogel-based materials for building applications: Influence of granule size on thermal and acoustic performance. Energy and Buildings, 152, 472-482. https://doi.org/10.1016/j.enbuild.2017.07.071

de Azevedo, A. R. G., Alexandre, J., Pessanha, L. S. P., Manhães, R. D. S. T., Brito, J., \& Marvila, M. T. (2019). Characterizing the paper industry sludge for environmentally-safe disposal. Waste Management, 95, 43-52. https://doi.org/10.1016/j.wasman.2019.06.001

Delany, M. E., \& Bazley, E. N. (1970). Acoustical properties of fibrous absorbent materials. Applied Acoustics, 3(2), $105-116$. https://doi.org/10.1016/0003-682X(70)90031-9

Donmez Cavdar, A., Yel, H., Boran, S., \& Pesman, E. (2017). Cement type composite panels manufactured using paper mill sludge as filler. Construction and Building Materials, 142, 410-416. https://doi.org/10.1016/j.conbuildmat.2017.03.099

Doudart de la Grée, G. C. H., Yu, Q. L., \& Brouwers, H. J. H. (2018). Upgrading and evaluation of waste paper sludge ash in ecolightweight cement composites. Journal of Materials in Civil Engineering, 30(3), 04018021. https://doi.org/10.1061/(ASCE)MT.1943-5533.0002186

Doutres, O., Salissou, Y., Atalla, N., \& Panneton, R. (2010). Evaluation of the acoustic and non-acoustic properties of sound absorbing materials using a three-microphone impedance tube. Applied Acoustics, 71(6), 506-509. https://doi.org/10.1016/j.apacoust.2010.01.007

Frías, M., Rodríguez, O., \& Sánchez de Rojas, M. I. (2015). Paper sludge, an environmentally sound alternative source of MKbased cementitious materials. A review. Construction and Building Materials, 74, 37-48. https://doi.org/10.1016/j.conbuildmat.2014.10.007

Gayathri, R., Vasanthakumari, R., \& Padmanabhan, C. (2013). Sound absorption, thermal and mechanical behavior of polyurethane foam modified with nano silica, nano clay and crumb rubber fillers. International Journal of Scientific \& Engineering Research, 4(5), 301-308.

Goel, G., \& Kalamdhad, A. S. (2017). An investigation on use of paper mill sludge in brick manufacturing. Construction and Building Materials, 148, 334-343. https://doi.org/10.1016/j.conbuildmat.2017.05.087

Horoshenkov, K. V. (2017). A review of acoustical methods for porous material characterisation. International Journal of Acoustics and Vibrations, 22(1), 92-103. https://doi.org/10.20855/ijav.2017.22.1455

Horoshenkov, K. V., \& Swift, M. J. (2002). The acoustic properties of granular materials with pore size distribution close to lognormal. The Journal of the Acoustical Society of America, 110(5), 2371-2378. https://doi.org/10.1121/1.1408312

Malaiskiene, J., Kizinievic, O., Kizinievic, V., \& Boris, R. (2018). The impact of primary sludge from paper industry on the properties of hardened cement paste and mortar. Construction and Building Materials, 172, 553-561. https://doi.org/10.1016/j.conbuildmat.2018.04.011

Miki, Y. (1990). Acoustical properties of porous materials. Modifications of Delany-Bazley models. Journal of the Acoustical Society of Japan (E), 11(1), 19-24. https://doi.org/10.1250/ast.11.19

Panneton, R. (2017). Overview of the porous material characterisation methods and impedance tube measurements. In Denorms training school 3 "Experimental techniques for acoustic porous materials and metamaterials". Le Mans.

Panneton, R., \& Olny, X. (2006). Acoustical determination of the parameters governing viscous dissipation in porous media. The Journal of the Acoustical Society of America, 119(4). https://doi.org/10.1121/1.2169923

Pfretzschner, J. (2002). Rubber crumb as granular absorptive acoustic material. Sociedad Española de Acústica. http://hdl.handle.net/10261/7999

Pfretzschner, J., \& Rodriguez, R. M. (1999). Acoustic properties of rubber crumbs. Polymer Testing, 18(2), 81-92. https://doi.org/10.1016/S0142-9418(98)00009-9

Sánchez-Orgaz, E. M., Denia, F. D., Baeza, L., \& Kirby, L. (2019). Numerical mode matching for sound propagation in silencers with granular material. Journal of Computational and Applied Mathematics, 350, 233-246. https://doi.org/10.1016/j.cam.2018.10.030

Shumway, G. (1960). Sound Speed and absorption studies of marine sediments by a resonance method. Geophysics, 25(2), 451467. https://doi.org/10.1190/1.1438717

Soucy, J., Koubaa, A., Migneault, S., \& Riedl, B. (2014). The potential of paper mill sludge for wood-plastic composites. Industrial Crops and Products, 54, 248-256. https://doi.org/10.1016/j.indcrop.2014.01.013

Sukontasukkul, P. (2009). Use of crumb rubber to improve thermal and sound properties of pre-cast concrete panel. Construction and Building Materials, 23(2), 1084-1092. https://doi.org/10.1016/j.conbuildmat.2008.05.021

Urick, R. J. (2005). The absorption of sound in suspensions of irregular particles. The Journal of the Acoustical Society of America, 20(3), 283-289. https://doi.org/10.1121/1.1906373 